\title{
EL DESARROLLO DEL ESTATUTO DE PERSONAJE DE CIDE HAMETE BENENGELI EN LAS CONTINUACIONES DEL QUIJOTE
}

1. El estudio del recurso que significa Cide Hamete Benengeli en el texto del Quijote nos ha sido sólo considerado en el plano de la ficción autorial. No han faltado cervantistas que han hablado del lugar que, con mayor o menor claridad, puede ocupar entre los demás personajes el falso autor de la obra. Así, Edward Riley ${ }^{1}$ observa que Benengeli es a un mismo tiempo personaje y narrador, y su situación de puente entre el lector y la historia original le permite distanciarse de ella para referirse mediante comentarios marginales a algunos aspectos que servirán para facilitar la predisposición del receptor. En todo caso, a Cide Hamete

«No se le permite materializarse tangiblemente en el mundo acerca del cual escribe, como lo hacen los que desempeñan un papel semejante al suyo en los relatos de Esplandián o La Lozana andaluzao".

César Rodríguez Chicharro ${ }^{3}$ significa la importancia del recurso en la medida en que es personaje-autor que le permite a Cervantes formular juicios de valor sobre su propia creación literaria de una forma en apariencia desinteresada, así como burlarse del recurso mismo y del resto de los personajes. Ruth El

\footnotetext{
1 EDWARD RILEY, «El recurso a los autores ficticios", en Teoría de la novela en Cervantes. Madrid, Taurus, 1966, pp. 316-327.

2 Op. cit., p. 321.

3 César Rodrfguez Chicharro, "Cide Hamete Benengeli», Anuario de Filología de la Universidad del Zulia, aa. 2-3, n.* 2-3, 1963-1964, pp. 195-234.
} 
Saffar ${ }^{4}$ estima que Benengeli se revela como personaje cuando él mismo o cualquiera de las restantes voces o personajes del Quijote hacen mención a ideas o acciones relacionadas con él y que no están referidas de una forma directa a la historia que, según la ficción autorial, está escribiendo el historiador arábigo. Tal vez, como después veremos, la situación más clara en este sentido sea la que apreciamos en el capítulo I, 16, momento en el cual se especula con el posible parentesco de Benengeli con el arriero amigo de Maritornes. Son también muestra de su condición de personaje sus intrusiones moralizantes en la novela y su situación como espectador de la vida de su protagonista. De esta forma,

«Every character-author in the novel became a character at the point at which he lost the sense of distance which held him apart from the work he was producing. Cide Hamete (...) has not escaped that tendency and therefore has not succeeded in mantaining absolute control over his novelistic world ${ }^{5}$.

Para Michel Moner ${ }^{6}$ ciertas señales como el posible y ya mencionado emparentamiento de Cide Hamete con el arriero apuntan a su naturaleza de personaje, pero los problemas de su voz autorial trascienden este estatuto.

2. Conocemos a los «sabios encantadores» de la literatura caballeresca como personajes integrados en el mundo de aventuras de los caballeros andantes. Merlín, Morgana, la Dama del Lago, Urganda, Arcaláus y Elisabad, entre otros, forman parte del ámbito caballeresco propiciando $u$ obstaculizando las empresas de Arturo, Lanzarote o Amadís. En algún caso, como en el del maestro Elisabad en las Sergas de Esplandián, el sabio encantador se hace cargo también de la memoria histórica de las hazañas del caballero protagonista.

Don Quijote acomoda todos sus pasos de caballero andante a la ortodoxia literaria definida por el corpus de los libros de caballerías que inspiran su misión. Tanto antes como después de que Cide Hamete Benengeli aparezca con su propio nombre en el texto del Quijote, el protagonista de la obra presupone que su condición de caballero ha de completarse con la existencia de

' RUTH El SAFFAR, Distance and Control in Don Quixote: a study in narrative technique. Chapel Hill, North Carolina Studies in the Romance Languages and Literatures, 1975.

5 Op. cit., p. 136.

6 Michel Moner, Cervantes conteur. Ecrits et paroles. Madrid, Bibliothèque de la Casa de Velázquez, 1989. 
un sabio atento a sus hazañas, a sus necesidades y a su mundo particular, y no solamente en cuanto se refiere a la eventual narración de sus aventuras. Don Quijote llega a pensar que el nombre con que a él se refiere Sancho Panza — "Caballero de la Triste Figura" - bien puede ser una determinación del sabio encantador cuya presencia trascendente se presume:

«... el sabio a cuyo cargo debe de estar el escribir la historia de mis hazañas, le habrá parecido que será bien que yo tome algún nombre apelativo, como lo tomaban todos los caballeros pasados: cuál se llamaba el de la Ardiente Espada; cuál, el del Unicornio; aquél, de las Doncella; aquéste, el del Ave Fénix; el otro, el Caballero del Grifo; estotro, el de la Muerte; y por estos nombres e insignias eran conocidos por toda la redondez de la tierra. Y así, digo que el sabio ya dicho te habrá puesto en la lengua y en el pensamiento ahora que me llamases el $\mathrm{Ca}$ ballero de la Triste Figura, como pienso llamarme desde hoy en adelante.... ${ }^{7}$.

En otra ocasión probablemente más clara -la invención que Sancho hace de la visita a Dulcinea- don Quijote es contundente suponiendo que, de ser las cosas como deben ser en el mundo caballeresco, el sabio en cuestión actúa como un colaborador personal de él mismo y de su escudero:

«¿Sabes de qué estoy maravillado, Sancho? De que me parece que fuiste y veniste por los aires (...) por lo cual me doy a entender que aquel sabio nigromante que tiene cuenta con mis cosas y es mi amigo (porque por fuerza le hay, y le ha de haber, so pena que yo no seria buen caballero andante), digo que este tal te debió de ayudar a caminar, sin que tú lo sintiesesw ${ }^{8}$.

«Por fuerza le hay, y le ha de haber». Es, pues, necesario que haya un sabio encantador que, parafraseando al protagonista, "tenga cuenta con sus cosas". A partir de esta impresión de don Quijote, consecuente con los parámetros que acotan la personalidad del estatuto ortodoxo de la andante caballería, el sabio que inventa, el sabio que cree omnipresente y que no es, desde luego, el modelo de sabio que encarna Cide Hamete Benengeli, estaría plenamente incardinado en el ámbito de los personajes. Del mismo modo que Merlín propicia con su magia el galope nocturno del rey Uther Pendragón, que cabalga a través de la niebla dirigiéndose, bajo la apariencia del Duque de Cornualles, al lecho de la bella Igraine, el sabio creado por la desmesurada imagina-

${ }^{7}$ Quijote, I, 19. Citamos siguiendo la edición de Martín de Riquer en Barcelona, Planeta, 1980.

${ }^{8}$ Quijote, I, 31. 
ción de don Quijote facilita el vuelo de Sancho en pos de una embajada de amor.

Pero el único sabio de cuya existencia sabemos, Cide Hamete Benengeli, reúne sólo una de las dos capacidades que en una misma persona espera don Quijote. El sabio que corresponde a la cosmovisión caballeresca del protagonista es aquel que aglutina dos actitudes complementarias - claramente enunciadas por el propio don Quijote en los dos primeros fragmentos transcritosy se comporta con arreglo a ambas: la primera consiste en la misión de escribir la historia de sus hazañas, según lo que es propio de un «sabio historiador", y la segunda consiste en prestar su ayuda al caballero y allanarle el terreno en el que galopa en pos de sus aventuras, lo cual es tarea de un "sabio encantador". Cide Hamete Benengeli no es un "sabio encantador", sino sólo un "sabio historiador", y por lo tanto no actúa, en el sentido pleno de la palabra, como un personaje.

A partir del estudio del autor ficticio parece clara su naturaleza de recurso paródico con funciones narrativas e incardinado en el aparato narratico del texto como uno de sus principales soportes. Sin embargo Benengeli roza el estatuto de personaje cuando tiene lugar la declaración que, basándose en fuentes indefinidas, realiza el narrador sobre el posible emparentamiento del autor arábigo con el arriero amigo de Maritornes, tal vez morisco con arreglo a lo corriente entre los arrieros de la época de Cervantes:

*... según lo dice el autor desta historia que deste arriero hace particular mención, porque le conocía muy bien, y aun quieren decir que era algo pariente suyow 9 .

Igualmente podriamos considerar en el sentido anterior los momentos en los cuales los protagonistas convierten a Cide Hamete en objeto de reflexión durante los capítulos iniciales del Quijote de 1615, si bien en este caso cabe destacar principalmente su naturaleza de tema de comentario por parte de los personajes más que una probable estimación como personaje propiamente dicho.

Cide Hamete Benengeli no aparece en el texto del Quijote como un personaje en toda la extensión del término, y desde luego no es el coadyuvante cuya intercesión espera don Quijote. El falso mago Merlín que aparece sobre la carreta en el capítulo II, 35 y le prescribe a los protagonistas un destino inventado sí responde al modelo de sabio encantador que necesita don Qui-

\footnotetext{
${ }^{9}$ Quijote, I, 16.
} 
jote, razón por la cual éste acata sus designios, paródicamente fatales para las posaderas de Sancho, sin discusión alguna, mientras que llega a dudar de Cide Hamete Benengeli, que cumple sólo las funciones de «sabio historiador":

«... desconsolóle pensar que su autor era moro, según aquel nombre de Cide; y de los moros no se podía esperar verdad alguna, porque todos son embelecadores, falsarios y quimeristas» ${ }^{10}$.

Don Quijote, que pretende ser un caballero andante y reproducir en cada uno de sus actos la ortodoxia literaria de los libros de caballerías, precisa de un sabio que reúna en su persona las habilidades mágica e historiográfica; un sabio como el maestro Elisabad del Amadís y las Sergas de Esplandián. Por lo que respecta a Cervantes, le resulta imprescindible la acción historiográfica de su sabio para plantear el entramado pseudohistórico a partir del recurso, y no le es forzoso en cambio desarrollar las virtuales funciones mágicas de un «sabio encantador" porque la imaginación de su protagonista le es más que suficiente.

3. Según lo que hemos expuesto más pormenorizadamente en otra ocasión "1", entendemos por continuaciones aquellas novelas en las que se narran sucesos protagonizados por los personajes quijotescos con posterioridad al tiempo delimitado por la historia de la vida caballeresca de don Quijote en la obra original cervantina. Las continuaciones se dividen en dos grupos, según que sean posteriores al Quijote de 1605 o al de 1615, y estas últimas se subdividen en ortodoxas o conservadoras y heterodoxas, según que no alteren el final del segmento histórico definido por la vida del protagonista o, por el contrario, pasen por alto su muerte devolviéndolo a la vida mediante la carga de inmortalidad que emana de su propia gloria o a través de los poderes taumatúrgicos de la resurrección.

El estatuto de personaje de Cide Hamete Benengeli, simplemente esbozado en la obra original, es singularmente desarrollado en tres continuaciones publicadas en los siglos XVIII y XX. Las Adiciones a la Historia del Ingenioso Hidalgo Don Quixote de la

10 Quijote, II, 3.

11 Santugo Alfonso López Navia, "Contra todos los fueros de la muerte. Las resurrecciones de don Quijote en la narrativa quijotesca hispánicaw, en Actas del II Coloquio Internacional de la Asociación de Cervantistas, Alcalá de Henares, noviembre de 1989 (en prensa). 
Mancha... ${ }^{12}$ de Jacinto María Delgado, primera de las obras que nos interesan, aparecen en el año 1786. Se trata de una continuación conservadora protagonizada por Sancho Panza, desconsolado tras la muerte de su amo, que es llamado al palacio ducal -recuérdese el segmento narrativo comprendido entre los capítulos XXX y LVII del Quijote de 1615- para asumir, tras un ceremonial absurdo, las funciones de consultor de palacio. Resulta destacable el progreso nobiliario de quien fuera escudero, que conquistará en la obra que protagoniza la honra de ser nombrado Barón de Casa-Panza.

A la vista de todas las continuaciones que hasta el momento hemos estudiado no nos cabe la menor duda de que las Adiciones de Delgado es la obra que mejor y más detalladamente conserva las funciones originales de Cide Hamete Benengeli, pero es obvio que la novedad principal que aporta esta novela a los valores textuales del autor ficticio es la de estar atribuida a un historiador que, a su vez, se convierte en objeto de atención historiográfica como protagonista de un opúsculo añadido a las Adiciones, lo que sin duda enriquece el entramado recursivo de la ficción autorial. Nos referimos a las Memorias del esclarecido Cide-Hamete Benengeli, autor celebérrimo de la Historia del Ingenioso Hidalgo Don Quixote de la Mancha. Recogidas por Melique Zulema, Autor igualmente verdadero que arábigo, cuya traducción hay que atribuir, siguiendo el recurso iniciado en las Adiciones, al propio Delgado, y que están editadas formando parte del mismo volumen. El breve apéndice que ahora comentamos está formado por dieciséis párrafos numerados que se extienden a lo largo de dieciocho páginas. En esta "biografía", atribuida a otro "autor igualmente verdadero que arábigon, se nos brinda un panorama que abarca tanto la vida como la obra de Cide Hamete Benengeli.

Melique Zulema inicia su recorrido biográfico ocupándose de la ascendencia y primeros años de Benengeli. Nos da cuenta de su nombre y su significado - "Cide" quiere decir "capitán"- y nos ofrece una descripción cumplida de Cide Hamete tanto en el plano físico como en el caracterológico. Resulta significativo, por lo que a su carácter se refiere, que su genio fuera «alegre,

12 Jacinto M.: Delgado, Adiciones a la historia del Ingenioso Hidalgo Don Quixote de la mancha, en que se prosiguen los sucesos ocurridos a su escudero el famoso Sancho Panza, escritas en arábigo por Cide Hamete Benengeli, y traducidas al castellano con las memorias de la vida de éste por D... Madrid, en la Imprenta de Blas Román, 1786. Utilizamos la edición facsimilar publicada por el Grupo Editorial Babilonia en Madrid, 1984. 
chancero y aficionado a burlasw ${ }^{13}$, lo que explica aventuras quijotescas tan peculiares como la de la doncella Altisidora o la de los gatos en las rejas del palacio ducal. Su oficio principal, aprendido en su infancia, era el de sastre, y como tal intervino en la confección de los vestidos que se emplearon durante la estancia de don Quijote en el palacio ducal:

"Y a la verdad sirvió bien esta habilidad de Cide Hamete en casa de los Duques, porque él ideó los trages que sirvieron para las distintas transformaciones que aparecen en la historia de Don Quixote, de varias colgaduras viejas que le dieron para este efecton ${ }^{14}$.

Es evidente la importancia del breve fragmento anterior: Cide Hamete es un personaje aparte de un historiador, y un personaje que toma parte en los detalles formales correspondientes a determinados lances. Esta participación aproxima al autor arábigo a la esfera de sus mismos objetos de interés ganando en proximidad y humanización lo que pierde en trascendencia, porque posee ciertas habilidades tocantes a la materialidad de los protagonistas de su historia.

Benengeli viene a parar a palacio después de ser vendido a los duques por un capitán español que dio al traste con su corta carrera de corsario. En su estancia en el palacio ducal alternó su principal oficio de alfayate con la cocina -otra de sus especialidades- y la escritura del Quijote, que había comenzado años atrás en tierras aragonesas.

«pues en el tiempo que estuvieron en Aragón se había dedicado a escribir los hechos del ingenioso hidalgo Don Quixote de la Mancha, que en aquel tiempo andaba desfaciendo agravios, y enderezando tuertos con general aplauso, y no los había continuado por haberse divertido en otras ocupaciones, a su parecer, más útiles, bien que guardaba en apuntaciones la continuación de sus aventuras (...) Muchas veces decía que sus amos los Duques lo quisieron mucho; pero aún más el Mayordomo, quien le hacía partícipe de varias confianzas domésticas, y de algunas empresas de consideración, no siendo la menor la de concederle tiempo y proporción para que continuase la historia de Don Quixote, con arreglo a sus apuntaciones, y otras que el mismo Mayordomo le dio, y había hecho de orden de los duques, desde que la fortuna había deparado el feliz encuentro de los principales héroes della en la caza de altaneria..... ${ }^{15}$.

${ }^{13}$ Op. cit., párrafo 6, p. 360.

14 Op. cit., párrafo 8, pp. 362-363.

15 Op. cit., párrafo 10, pp. 366-368. 
Cide Hamete, que según Melique Zulema era además un notable tañedor de pandero de cascabel y gaita gallega, hasta el punto de que se le atribuye a él la invención del bajo de moscón de este último instrumento, se nos aparece, de esta manera, como un testigo de las andanzas de don Quijote y en su propio tiempo, hecho que lo autoriza sobradamente para tomar la pluma como el historiador versado que demuestra ser.

Al conseguir su libertad comparte varias jornadas de su viaje de regreso a su tierra con el lacayo Tosillos, el mismo que, si recordamos el capítulo II, 56 de la obra cervantina, tuvo que enfrentarse a don Quijote por el honor de la hija de doña Rodríguez sin que el combate llegara finalmente a celebrarse.

Mediante las informaciones recogidas en las Memorias del esclarecido Cide-Hamete Benengeli se consigue un importante desarrollo del estatuto de personaje del historiador árabe. Jacinto María Delgado pone en la pluma solícita de Melique Zulema una narración fresca y entretenida que amplía de forma sorprendente aquella tímida revelación que en el capítulo I, 16 del Quijote aproximaba a Cide Hamete a un personaje tan marginal y poco presente en la obra como era el arriero.

En el año 1905 se publica Don Quijote en América ${ }^{16}$, novela del escritor ecuatoriano Tulio Febres Cordero que, con arreglo a lo que expusimos anteriormente, supone una continuación heterodoxa muy significativa por lo que respecta al estatuto de personaje del sabio historiador del Quijote. El resumen del argumento es una buena prueba de lo que decimos: el mismísimo hijo de Cide Hamete Benengeli preside el traslado de don Quijote, encantado después de su muerte junto con Sancho Panza, a la cueva de Montesinos, de donde será involuntariamente liberado por un pastorcillo de Montiel. Benengeli, pues, cobra entidad de personaje e interviene a través de su hijo, a quien, en cumplimiento de la voluntad del mago Merlín, encarga de depositar a los protagonistas en su mágico paradero, desde donde saldrán liberados para pasar a vivir nuevas aventuras en tierras de América.

Notemos que quien en la obra original no pasaba de ser un "sabio historiador" adquiere ahora atribuciones propias del «sabio encantador" que formaba parte del universo caballeresco de don Quijote. Ahora Cide Hamete, parafraseando las palabras del protagonista de la obra cervantina, sí "tiene cuenta con sus cosas" en el sentido pleno de la expresión y no sólo en lo que respecta

${ }^{16}$ TUlio Febres Cordero, Don Quijote en América, o sea, la cuarta salida del ingenioso hidalgo de la Mancha Caracas, Parra León hermanos, editores, 1930. Esta es la edición que manejamos, pero nos consta por la lectura de los preliminares que la primera está fechada en el año 1905. 
a la memoria histórica de sus hazañas, desde el momento en que interviene a través de su hijo en cumplimiento de la mágica voluntad de Merlín, mago de magos y "sabio encantador" por antonomasia:

"-iBendito sea Alá por tres veces! - dijo entonces con gran satisfacción el gallardo doncel- porque cumplidos están los secretos designios del sabio encantador Merlín, comunicados a mi padre Cide Hamete Benengeli, de que reposéis y durmáis en esta oculta morada, oh, ilustre manchego, acompañado de vuestro adicto escudero, hasta que suene la hora de vuestro reaparecimiento en el mundo, para continuar en el otro hemisferio la obra iniciada en éste.... ${ }^{17}$.

El propio Benengeli actúa directamente en el plano de los personajes mostrando su interés por los protagonistas, convirtiendo en realidad las intuiciones del don Quijote cervantino acerca de una fuerza mágica que, bajo la apariencia de un sabio encantador, rige a distancia sus pasos de caballero:

"Variando el camino que había llevado y caminando más de noche que de día, llegaron a la costa y se hicieron a la vela para el Africa, donde el árabe Cide Hamete estaba ansioso de su regreso, por lo mucho que le importaba tener en seguro a los principales personajes de su historia» ${ }^{18}$.

La última obra que nos interesa en relación con el tema que ahora estudiamos es Don Quijote en Yanquilandia ${ }^{19}$, novela de Juan Manuel Polar publicada en el año 1925. Se trata de una original continuación heterodoxa en la que don Quijote entra en los sueños del mismísimo tío Sam, dormido tras la lectura de la novela cervantina, para reclamar el concurso y esfuerzo imprescindibles con objeto de devolver a la vida al caballero y a su escudero. Una vez obrado el milagro de la resurrección don Quijote encuentra en los Estados Unidos del siglo XX un nuevo contexto en el que vivir nuevas hazañas desde su singularísima perspectiva.

Cide Hamete Benengeli aparece en Don Quijote en América como autor de un inevitable manuscrito en el que se contienen las nuevas aventuras del protagonista, pero en el despliegue funcional del recurso también es tratado por Polar como un personaje que trasciende a su propia historia y, en razón de sus atribuciones mágicas de sabio encantador,ha prevalecido en un

17 Op. cit., p. 39.

18 Op. cit., p. 40.

19 Juan Manuel Polar, Don Quijote en Yanquilandia. Cartagena, Ed. Juvenilia, 1925. 
estadio cronológico paralelo definido por las inaprehensibles coordenadas de la intemporalidad para dejar oír su voz en nuestro tiempo mostrando, con su voluntad de autor, una indiscutible coherencia con las declaraciones finales del último capítulo del Quijote cervantino. 0 lo que es igual: nadie más que él disfruta de los derechos de autor en virtud de los cuales no se puede discutir la legítima libertad de dar a la luz las nuevas andanzas de sus personajes adoptando el método que le parezca más conveniente. Y el método elegido nos lo comunica Polar, editor y traductor de un manuscrito que le hace llegar el propio autor indiscutible de la obra:

«Dicho se está, pues, lector curioso, que esta no es novela sino historia, cuyos datos y apuntes tomélos de un cierto manuscrito arábigo que no sé cómo ni cómo no vino a mis manos traído por el correo que llaman de la "mala real"; y mala resultó ser para mí, pues me trujo la encomienda de sacar a la luz la historia de la resurrección de don Quijote (...); pero es el caso que con el manuscrito venía una carta o misiva de Cide Amete <sic> Benengeli, el cual con muchos encarecimientos y exhortaciones me apremiaba para que viese de componer este libro con los datos y apuntes del manuscrito arábigo que antes dije; y mal año para mí por descortés y majadero si anduviese con excusas y reparos cuando historiador de tanta fama y nombradía me hacía la merced de tomarme por traductor y copistaw ${ }^{20}$.

Así pues, el estatuto de persojane de Cide Hamete Benengeli, simplemente esbozado en el Quijote, es desarrollado con mayor o menor extensión en la literatura quijotesca. Delgado convierte al autor ficticio en objeto de interés histórico a través de las $\mathrm{Me}$ morias del esclarecido Cide Hamete Benengeli, significando que su experiencia próxima a la acción de los restantes personajes de la obra original justifica algunos hechos que afectan a la elaboración del texto. En Don Quijote en América Benengeli toma parte en los momentos iniciales de la obra evidenciando condiciones y poderes mágicos de "sabio encantador" que no fueron contempladas en ningún momento de la obra original. Por fin, en Don Quijote en Yanquilandia, última de las obras que hemos estudiado, Cide Hamete Benengeli extiende su acción fuera de su misma obra al comunicarse epistolarmente con el editor y traductor de su nuevo manuscrito, con lo que se incorpora como personaje a una parte, mínima pero representativa, de la novela de Polar.

Parece como si los continuadores del Quijote no se conformaran con la voluntad creativa de Cervantes y complementaran

${ }^{20}$ Op. cit., pp. 5-6. 
las funciones de Benengeli reforzándolo con atribuciones que lo hacen presente en su propia obra. Esto demuestra una vez más que quienes han seguido la línea literaria trazada por el texto cervantino han entendido el peso específico del recurso cuyo espectro funcional están ampliando. Considerando los textos que hemos estudiado hasta el momento creemos estar en condiciones de afirmar que el recurso del autor ficticio, con su pervivencia, variantes y menciones, es el más presente a lo largo de cuatro siglos de continuaciones, ampliaciones e imitaciones del Quijote. Las tres obras que hemos seleccionado para nuestro estudio son sólo una muestra cuyo interés está basado en el hecho de que significan un complemento original de los valores literarios de Cide Hamete Benengeli, que además de no resignarse a guardar silencio, se ha aventurado a dejar la señal de su presencia en las nuevas páginas.

SANTIAgo Alfonso LÓPEz NAvia 